\title{
O SISTEMA ÚNICO DE SAÚDE (SUS): CONSELHO MUNICIPAL DE SAÚDE E A GESTÃO PARTICIPATIVA
}

\author{
ADRIANA CÉLIA COSTA ${ }^{1}$, FRANCILAYNE BRAGA ${ }^{1}$, MARCOS LUPÉRCIO RAMOS $^{2}$ \\ ${ }^{1}$ Discente da Faculdade de Ciências da Saúde de Presidente Prudente - Curso de Enfermagem - UNOESTE. ${ }^{2}$ Docente \\ da Faculdade de Ciências da Saúde de Presidente Prudente - Curso de Enfermagem - UNOESTE. E-mail: \\ lupercioramos@yahoo.com.br
}

\section{RESUMO}

A presente pesquisa procura destacar e contribuir para a análise das condicionantes históricas da constituição do sistema público de saúde no país. Os estudos procuravam refletir sobre o atual sistema em termos de sua gestão e participação coletiva com proposta de oferta de saúde para todos com qualidade a partir de uma escala local. Dentro dessa análise, foram destacadas questões relacionadas aos direitos e deveres dos gestores e dos usuários - quais são - e como pode ocorrer o exercício da cidadania representado pelos mecanismos gestacionais de participação coletiva, quais sejam, os conselhos municipais de saúde a partir do estudo de uma unidade administrativa, o município de Martinópolis-SP. Considera-se importante essa análise da gestão do SUS, pois o sistema envolve, em termos operacionais e gestacionais, princípios essenciais à sociedade, como a democracia, igualdade e universalidade, sendo importante a discussão desse universo para o(a) profissional da enfermagem.

Palavras-chave: Conselho Municipal de Saúde; Gestão da Saúde; Participação coletiva.

\section{INTRODUÇÃO}

Para se entender o desenvolvimento do sistema de saúde pública no Brasil, em específico a criação do SUS (Sistema Único de Saúde), é preciso conhecer as legislações que abordam a questão na atualidade, interpretá-las e desmistificá-las, a luz processo histórico envolvido, podendo-se assim, construir mecanismos que possam contribuir para que outros cidadãos possam entender melhor a estrutura de funcionamento do sistema.

Procurando entender o construto histórico da saúde pública brasileira, Bertolli (2008) comenta que no período histórico do Brasil-Colônia pouco se fez em termos de implantação de um sistema público de saúde e muito menos ainda em termos de gestão da saúde. Somente com a vinda da corte portuguesa para o Brasil em 1808 provoca mudanças na administração pública colonial, inclusive na área da saúde. Como sede do império, a cidade do Rio de Janeiro tornou-se centro de algumas ações sanitárias. Em decorrência da vinda de boa parte da elite portuguesa ao Brasil, criou-se a necessidade de formação de novos médicos. Em 1813 no Rio de Janeiro, e 1815 na Bahia, foram fundadas academias para a formação de médicos e nesta época surgiu a junta de higiene pública a qual, apesar de várias reformulações, não alcançou o objetivo de cuidar da saúde 
da população como um todo, estando restrito - esse atendimento - às camadas mais privilegiadas da população. Em termos de gestão da saúde de forma democrática, não houve acenos nesse sentido, permanecendo burocrática e centralizada no pouco que oferecia.

Pouco a pouco as políticas em torno da área da saúde vão sendo construídas conforme ocorriam às trocas de governo mais algumas décadas ainda seriam necessárias para que essas políticas se consolidassem e caminhassem pelo viés da democracia participativa. Fausto (1995) entende que, após a segunda guerra mundial, com o fim da ditadura do governo de Getúlio Vargas e restituição dos princípios da eleição direta para os principais cargos políticos, pela liberdade de atuação da imprensa e dos sindicatos, o cenário de mudanças se consolidava, pois também a economia do país começava a sair de seu patamar eminentemente agrário e arcaico, para o universo industrial e moderno. Mas no que tange à saúde pública as mudanças não ocorrem na mesma proporção mesmo com o tema da política desenvolvimentista no governo de Juscelino Kubistchek, lembrado por Costa (1995) ou nos governos do período militar (1964-1984), em que cresceram as despesas com políticas de infraestruturas nos setores de transportes, indústria, agricultura e comércio, mas não na área de saúde pública.

Para Vasconcelos (2004, p. 68) a “'tranqüilidade' social imposta pela repressão política e militar permitindo que o regime voltasse suas atenções para a expansão da economia, diminuindo os gastos com as políticas sociais", suprimiu as mobilizações sociais e desorganizou as organizações civis, promovendo uma centralização ainda maior das políticas públicas para a saúde.

Cientes deste fato e do péssimo atendimento público à saúde da população, a sociedade civil e os profissionais do setor também se organizaram na defesa da profissão e dos direitos dos pacientes e das condições de trabalho. Esses movimentos e mobilizações resultam, ainda no final de 1970, no surgimento da Associação Brasileira de Pós - Graduação em Saúde Coletiva (ABRASCO) e do Centro Brasileiro de Saúde (CEBES). A partir dessas associações, ocorre o chamado movimento sanitarista que buscou encontrar respostas para os dilemas das políticas de saúde nacional, tendo sido elaborado um documento intitulado "pelo direito universal da saúde" que o acesso a assistência é direito do cidadão e dever do estado, descrito no art.196 da constituição de 1988 (BERTOLLI, 2008, p. 63).

Na constituição de 1988 (São Paulo, 2011), encontram-se artigos que prescrevem a criação do SUDS (Sistema Unificado e Descentralizado de Saúde), pelo qual as redes públicas e particulares de atendimento à saúde deveriam constituir uma rede hierarquizada e regionalizada, com a participação da comunidade das unidades locais. 
Para Stralen (Et. al, 2006), Ana Maria Costa e Tatiana Lionço (2006, p. 48) a “[...] consolidação do Sistema Único de Saúde requer a renovação permanente de iniciativas que visem resgatar, assegurar e implementar os seus princípios [...]", quais sejam, da universalidade, da equidade e da integralidade, para tanto, a gestão participativa é instrumento fundamental e democratizador. Mas o importante - embora há muito por se fazer ainda - chegou-se a atual estruturação e gestão do SUS que permite a participação da população usuária na gestão, assim colocado por Puccia (2007, p.17):

[...] Conselhos e Conferencias de Saúde: de acordo com a lei orgânica de saúde (lei $\left.n^{\circ} 8080 / 1990\right)$ dos quais são os princípios universalidade, integralidade e equidade e a lei $n^{\circ} 8142 / 1990$ que ficou estabelecida a forma de participação da sociedade no setor de saúde por cada uma das três esferas de governo.

Os profissionais de enfermagem são personagens importantes dentro da estruturação e funcionabilidade do Sistema Único de Saúde (SUS), dessa maneira, não podem estar alheios aos acometimentos tecnológicos, científicos, políticos e econômicos que envolvem o universo da prestação de saúde pública no Brasil. É preciso que não se preocupem apenas com o cuidar, função básica da profissão, mas também em entender os processos que levam pessoas à necessidade de serem cuidadas. É preciso aprender a olhar os contrastes e/ou contradições que permeiam as relações sociais e que podem interferir nos múltiplos ambientes que propõem à prestação de serviços em saúde (FIGUEIREDO e TONINI, 2010).

Destaca-se também que, para a ocorrência do processo participativo e, portanto, democrático na gestão da saúde, é importante um processo educativo, conforme salientam Vasconcelos (2004) e Pedrosa (2008), tanto dos profissionais enfermeiros quanto dos demais membros dos Conselhos Municipais da Saúde e da população de maneira geral. Aprimorar processos educativos, dessa maneira, tornam-se necessários.

Caminhando nesse sentido - do aprimoramento educativo - é que torna justificável a realização de pesquisas acadêmicas, pois não se pode aprimorar o sistema de saúde em questão sem o devido conhecimento de seus processos de implementação, daí a necessidade constante das revisões bibliográficas sobre o tema e de estudos de casos. É preciso a educação permanente em termos da coletividade e controle da individualidade, por isso, o conhecimento e a divulgação de mecanismos de participação coletiva como os que se propõe para a gestão do Sistema Único de Saúde no Brasil são importantes e pesquisas na área promovem análises mais amplas da questão. Com essa preocupação, o objetivo geral dessa pesquisa foi analisar e refletir sobre a gestão do 
Sistema Único de Saúde (SUS) em termos de gestão participativa, em um município - MartinópolisSP - a partir da percepção que os membros do Conselho Municipal de Saúde (CMS) e profissionais da enfermagem, têm sobre essa temática.

\section{METODOLOGIA}

Esta pesquisa seguiu uma proposta qualitativa quando se propôs à interpretação e reflexão sobre os dados coletados, assim como, sem prejuízo do viés qualitativo, utilizou mecanismos que expressaram a abordagem quantitativa, uma vez que a sistematização dos dados coletados exigiu a síntese matemática/estatística dos mesmos representados por tabelas e gráficos.

Seguindo proposta de Duarte, Mamede e Andrade (2009), o método qualitativo seguiu mecanismos e/ou procedimentos disponíveis na técnica do Discurso do Sujeito Coletivo, tais como as entrevistas individuais feitas por meio de questionário.

A pesquisa procurou também trabalhar dentro da metodologia científica de Estudo de Caso, pois, conforme André (1995), objetiva estudar um determinado grupo social que representam um órgão específico e delimitado, que é o Conselho Municipal de Saúde de um município também específico e delimitado, no caso, Martinópolis-SP, assim como os profissionais de enfermagem do referido município.

Efetuou-se também a necessária revisão bibliográfica sobre a temática enfocada além da realização de entrevistas com o grupo selecionado: membros participantes do CMS/MartinópolisSP (13 pessoas) e 10 profissionais enfermeiros (as) do município sobre as condições e percepções em relação a participação no referido conselho gestacional.

A escolha pelo município de Martinópolis-SP para a coleta de dados mais concretos e exemplificativos sobre a participação em um conselho municipal de Saúde, se deu em decorrência dos discentes-pesquisadores residirem no lugar e, assim, terem mais facilidade em termos de tempo para a operacionalização das ações envolvidas para a coleta de dados.

\section{RESULTADOS}

Na constituição federal de 1988 e detalhadas nas leis orgânicas da Saúde (Lei n 8.080/90 e Lei $\mathrm{n}^{\circ}$ 8.142/90), foram fixados os princípios do SUS, que vieram coroar um longo processo histórico e social de lutas, mobilizações e reivindicações que buscavam mudanças nas condições de saúde e assistência prestadas a população brasileira. As principais mudanças ocorridas em termos do atendimento em saúde pública no Brasil estão consolidadas no processo de 
descentralização das responsabilidades, das atribuições e dos recursos para estados e municípios. Segundo Lecovitz; Lima e Machado (apud, CONASS, 2011, p. 32), para o "[...] processo de descentralização em saúde no Brasil [...]" há a necessidade de envolvimento e não só da "[...] transferência de serviços, mas também de responsabilidades, poder e recursos da esfera federal para a estadual e a municipal".

A partir desses pressupostos legais e princípios é que foi criado o Conselho Municipal de Saúde do município de Martinópolis-SP. A Lei de criação e atuação do Conselho Municipal de Saúde do município de Martinópolis-SP é a Lei Municipal no 015/91 de 18/07/91, tendo sido modificada pelas Leis Municipais de números: 2.083 de 28/11/96, 2.097 de 23/04/97 e 2.452 de 06/12/05. Por esse conjunto de leis municipais, o Conselho Municipal é composto por treze (13) membros que procuram representar diferentes setores da sociedade civil organizada e do setor público. Contando assim, com representantes do Setor Executivo (Poder Executivo Municipal); dos Prestadores de Serviços de Saúde; dos Trabalhadores de Saúde; dos Usuários da Vila Vicentina Frederico Ozan; dos Usuários da Igreja Evangélica; dos Usuários da Associação Comercial; dos Usuários do Rotary; dos Usuários da Igreja Católica; dos Usuários da Associação Jesus Vem Nos Salvar e dos Usuários do Departamento de Educação.

O tipo de gestão municipal da saúde em Martinópolis-SP é o de habilitação Plena Atenção Básica tendo sido ortogado em 07/04/1998. Segundo o Plano Municipal de Saúde (2010), as ações desenvolvidas envolvem programas de Atendimento a Criança e ao Adolescente; Saúde da Mulher; Saúde do Idoso; Hipertensão e Diabetes; Saúde Bucal; Saúde Mental; Assistência Farmacêutica; Vigilância Sanitária e Vigilância Epidemiológica. Em termos de promoção à saúde de maneira direta a população com atendimento clínico e ambulatorial, o município possui uma rede de atendimento composta por uma Unidade Básica de Saúde (UBS), e cinco unidades de Estratégia de Saúde da Família (ESF) contando com cinco de equipes o que proporciona a cobertura de 62.08\% da população do município. Possuindo também, trinta e seis agentes comunitários (ACS), três equipes de Saúde Bucal e um CAPS (Centro de Apoio Psicossocial).

No Plano Municipal de Saúde (2010) e na Lei de criação e funcionamento do Fundo Municipal de Saúde, $\mathrm{n}^{\circ}$ 1.779/91, há o estabelecimento de políticas e investimentos na área de saúde no município em Saúde Mental; Saúde Bucal; Assistência farmacêutica e Humanização e qualificação da atenção à saúde do Idoso. Constando também metas como a redução da mortalidade infantil; construção de 04 prédios da ESF; construção de 06 consultórios odontológicos e equipamentos; o aperfeiçoamento do atendimento fisioterápico; reforma e 
ampliação da estrutura física e dos equipamentos para ESF Felintra Alves dos Santos e Josenaldo José de Medeiros.

A partir da análise do Plano Municipal de Saúde (2010) de Martinópolis-SP, percebe-se que o município atende, no aspecto legal e dos princípios da gestão da saúde pública, os pressupostos elencados para a descentralização e atendimento da saúde. Mas se fazia necessário se, na percepção dos membros do conselho municipal de saúde e dos (as) profissionais de enfermagem do município isso também ocorria. Para tanto foram entrevistados doze (12) dos treze (13) membros do Conselho Municipal de Saúde de Martinópolis-SP, assim como 10 enfermeiras(os) que trabalham na rede municipal de saúde local.

Considerando a questão da gestão em três níveis (federal, estadual e municipal), pode-se dizer que a maioria dos entrevistados considera esse aspecto como bom, sendo ressalvado, principalmente quando se referiram à gestão níveis federal e à gestão estadual, que a situação da saúde pública seria melhor se houvesse mais agilidade nos processos burocráticos e maior oferta de recursos.

Quando confrontados sobre a participação do Conselho Municipal de Saúde de Martinópolis-SP na gestão da saúde pública no município, são unânimes - tanto os conselheiros como os profissionais da enfermagem - em dizerem que a mesma é boa, importante e que contribui para a melhoria dos serviços de saúde pública prestada aos usuários.

\section{CONCLUSÃO}

Considerando a análise histórica efetuada com a revisão bibliográfica, percebe-se que a conquista para o estabelecimento de uma rede de assistência pública em saúde à população do Brasil enfrentou barreiras extremamente conservadoras de uma elite inicialmente agrária e depois industrial, bancária e comercial, insensível e refratária ao desenvolvimento sócio-econômico do país. Bertolli (2008) entre outros, destacam o processo da evolução da saúde pública em si no Brasil, Costa (1995), Fausto (1995) e outros, destacam os aspectos políticos e econômicos que ditam as regras do processo evolutivo da democracia participativa que irá atingir o ambiente da saúde a partir de 1988.

Há um período então, compreendido pelas primeiras medidas colocadas em 1808 pela corte portuguesa de 180 anos até 1988, ano da atual constituição federal, de busca constante da sociedade civil como um todo e dos profissionais da área da saúde pela efetivação de mecanismos que promulguem a participação social na gestão da saúde no país. 
Essa participação social na gestão da saúde, a exemplo do resultado das entrevistas com conselheiros e profissionais da enfermagem no município de Martinópolis-SP, é saudável e tem contribuído para a melhoria do sistema de saúde pública, a partir do momento em que há a possibilidade de maior fiscalização do sistema e também de ingerência nas políticas para o setor.

\section{REFERÊNCIAS}

ANDRÉ, MEDA de. Etnografia da prática escolar. Campinas-SP: Papirus, 1995.

BERTOLLI, C F. História da saúde pública no Brasil. São Paulo : 2008. 71 p.

CONASS, Coleção para entender a gestão do SUS. 1. ed. Brasília, 2011. Disponível em http://www.conass.org.br/colecao2011/livro 1.pdf. Acesso em 20 abr 2013.

COSTA, AM; LIONÇO, T. Democracia e Gestão Participativa: uma estratégia para a eqüidade em saúde? Saúde e Sociedade v.15, n.2, p. 47-55, maio-ago 2006. http://www.scielo.br/scielo.php?pid=S0104-12902006000200006\&script=sci arttext - Acesso em 20/12/12.

COSTA, WM. O Estado e as políticas territoriais no Brasil. São Paulo: Contexto, 1995.

DUARTE, SJrH; MAMEDE, MV; ANDRADE, SMO de. Opções Teórico-Metodológicas em Pesquisas Qualitativas: Representações Sociais e Discurso do Sujeito Coletivo. Saúde Soc. São Paulo, v.18, n.4, p.620-626, 2009. In: http://www.scielo.br/pdf/sausoc/v18n4/06.pdf - Acesso em 20/05/2013.

FIGUEIREDO, NMA; TONINI, T. SUS e PSF Para Enfermagem: Pratica para o cuidado em saúde coletiva 1a edição, São Paulo : Yendis, 2010.

MARTINÓPOLIS, Estado de São Paulo, Brasil. Plano Municipal de Saúde, período de 2010 a 2013. Editora: Prefeitura Municipal de Martinópolis, 2010, p. 2-55.

PEDROSA, JIS. EDUCAÇÃO POPULAR EM SAÚDE E GESTÃO ARTICIPATIVA NO SISTEMA ÚNICO DE SAÚDE.. Rev. APS, v. 11, n. 3, p. 303-313, jul./set. 2008.

PUCCIA, MIR. O enfermeiro como assessor federal, estadual e municipal. (In: Santos, AS; Miranda, SMRC. (Orgs) . A enfermagem na gestão em atenção primaria à saúde). Barueri : Manole, 2007. p. 63-80.

SÃO PAULO, Imprensa Oficial do Estado de. Constituição da República Federativa do Brasil, Constituição do Estado de São Paulo e Declaração Universal dos Direitos Humanos._São Paulo: Imprensa Oficial, 2011. In:

http://www.imprensaoficial.com.br/PortallO/download/pdf/Constituicoes declaracao.pdf Acesso em: 02/07/2012.

STRALEN, CJ; LIMA, ÂMD; SOBRINHO, DF; SARAIVA, LES; STRALEN, TBS; BELISÁRIO, SA. Conselhos de Saúde: efetividade do controle social em municípios de Goiás e Mato Grosso do Sul. Ciência \& 
Saúde Coletiva, 11(3):621-632, 2006. http://www.scielosp.org/pdf/csc/v11n3/30978.pdf - Acesso em 20/12/12.

VASCONCELOS, EM. Educação Popular: de uma Prática Alternativa a uma Estratégia de Gestão Participativa das Políticas de Saúde. PHYSIS: Rev. Saúde Coletiva, Rio de Janeiro, 14(1):67- 83, 2004. http://www.scielo.br/pdf/physis/v14n1/v14n1a05.pdf - Acesso em 20/12/12. 